\title{
Diabetes Mellitus: Is It Protective against Aneurysm? A Narrative Review
}

\author{
Kanchi Patel ${ }^{\mathrm{a}}$ Mohammad A. Zafar ${ }^{\mathrm{a}}$ Bulat A. Ziganshin ${ }^{\mathrm{a}, \mathrm{b}}$ \\ John A. Elefteriades ${ }^{a}$ \\ ${ }^{a}$ Aortic Institute at Yale-New Haven, Yale University School of Medicine, New Haven, CT, USA; \\ ${ }^{\mathrm{b}}$ Department of Surgical Diseases, Kazan State Medical University, Kazan, Russia
}

\section{Keywords}

Diabetes mellitus · Aortic aneurysm · Aortic aneurysm, thoracic · Aortic aneurysm, abdominal · Meta-analysis . Aortic rupture

\begin{abstract}
Objectives: In the course of extensive clinical aortic surgery, we noticed that the aorta was quite thick and fibrotic in diabetic patients. We thought the diabetic aortic aorta might be inimitable to aortic dissection. On this basis, we set out to review information in the literature regarding aortic growth and dissection in diabetic patients. Methods: We used a 2-step search approach to the available literature on diabetes and aneurysm. Firstly, databases including PubMed, Cochrane, Embase and TRIP were searched. Secondly, relevant studies were identified through secondary sources including references of initially selected articles. We address the relationship between diabetes and the incidence, prevalence, growth, mortality and rupture of an aneurysm. Results: Diabetes is thought to exert a protective role in both thoracic aortic aneurysm (TAA) and abdominal aortic aneurysm (AAA). Diabetics were shown to have a slower aneurysm growth rate, lower rupture rate, delayed (>65 years) age of rupture, decreased rate of mortality from an aneurysm and a decreased length of hospital stay. There
\end{abstract}

was also noted a decreased rate of incidence and prevalence of TAA and AAA in diabetics, smaller aneurysm diameter, reduction in matrix metalloproteinases and an increased aortic wall stress in diabetics. Antidiabetic agents like metformin, thiazolidinediones and dipeptidyl peptidase-4 inhibitors may protect against an aneurysm. Conclusion: Our literature review provides strong (but often circumstantial) evidence that diabetic patients exhibit slower growth of aortic aneurysms and a lower rate of aortic dissection. Furthermore, clinical and experimental studies indicate that common antidiabetic medications on their own inhibit growth of aortic aneurysms. These findings indicate a paradoxically beneficial effect of the otherwise highly detrimental diabetic state.

() 2018 S. Karger AG, Basel

\section{Introduction}

This paper reviews the evidence in favor of a paradoxical protective effect of diabetes mellitus (DM) in aortic aneurysm disease, both thoracic and abdominal.

Aortic aneurysm is the 19th leading cause of death in the USA [1]. Aortic aneurysms were the primary cause of 9,863 deaths in 2014 and a contributing cause in more than 17,215 deaths in the USA in 2009 [2].

\section{KARGER}

(C) 2018 S. Karger AG, Basel

E-Mail karger@karger.com

www.karger.com/crd
John A. Elefteriades, MD

Aortic Institute, Yale-New Haven Hospital

789 Howard Avenue

New Haven, CT 06510 (USA)

E-Mail john.elefteriades@yale.edu 


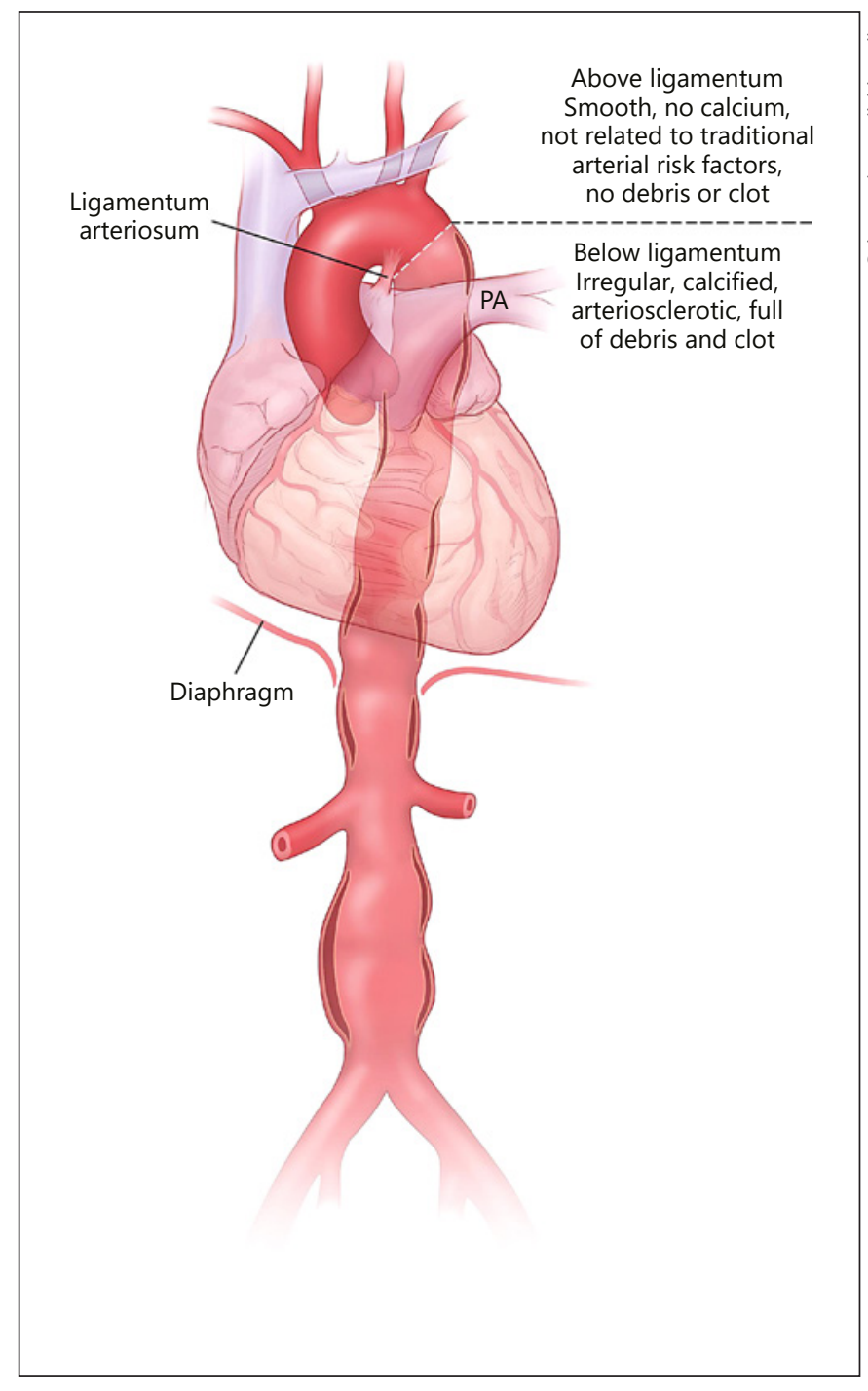

Fig. 1. Division of the aorta by the ligamentum arteriosum, separating aneurysm disease into two distinct entities of disparate morphology. PA, pulmonary artery. Reprinted with permission from Elefteriades and Farkas [3].

Aortic disease is naturally divided by the ligamentum arteriosum (Fig. 1). In aneurysm disease, the aorta proximal to the ligamentum is generally smooth, noncalcified, nonarteriosclerotic and strongly genetically mediated. In contrast, below the ligamentum, the aorta is irregular, calcified, arteriosclerotic and intimately related to traditional arteriosclerotic risk factors [3]. Atherosclerosis and hypertension are important contributors to the development of descending thoracic aortic and abdominal aortic aneurysm (AAA) $[4,5]$. Causation of ascending thoracic aortic aneurysm (TAA) is genetic or familial, with Mar- fan's syndrome being one of the major genetic causes [3]. Other genetic causes include Ehlers-Danlos syndrome, Loeys-Dietz syndrome, bicuspid aortic valve and familial aortic dissection [6]. This discrepancy between ascending and abdominal aneurysms could also be due to the absence of vasa vasorum in the abdominal aorta, making it more susceptible to injury due to lack/loss of nutrition to the aortic wall itself $[7,8]$.

Paradoxically, diabetes, which is a major risk factor for cardiovascular, cerebrovascular and peripheral vascular diseases, could potentially be protective against aneurysms. Surgeons have long noted that the diabetic aorta appears grossly thickened in the operating room, and dense and fibrous as well - perhaps inimitable to aortic dissection, which, by appearances, would have a hard time rending this dense aortic wall. There has been a longstanding suspicion that diabetes might have a preventive role not only in the presence, but also the growth of an aneurysm. This paper will be organized as follows. "Methods" will describe our literature search strategy. "Background" will discuss the pathophysiology of aneurysm formation. "Potential Mechanisms" will discuss biological pathways through which diabetes may be protective. Then, the sections on "Epidemiologic Impact," "Thoracic Aortic Aneurysm," and "Abdominal Aortic Aneurysm" will discuss specific experimental and clinical findings in aneurysm disease in general and in thoracic and abdominal subtypes specifically. Finally, "Drugs and Aneurysm" will explore the possibility that the drugs used to combat diabetes may in and of themselves exert protective effects against aneurysm development and progression. A table is provided which summarizes key experimental and clinical findings.

\section{Methods (Literature Search Strategy)}

We used a 2-step search approach to the available literature on diabetes and aneurysm. Firstly, databases including PubMed, Cochrane, Embase and TRIP were searched. Secondly, relevant studies were identified through secondary sources including references of initially selected articles (Fig. 2). Search terms used were: aortic aneurysm, thoracic; aortic aneurysm, abdominal; incidence; prevalence; aortic aneurysm; diabetes mellitus; growth; hyperglycemia; hypoglycemic agents; aortic aneurysm/drug therapy. We did not follow formal PRISMA guidelines (http://prisma-statement.org/) for this less formal overview of a complex and multifaceted topic. 
Fig. 2. Flowchart incorporating the algo-

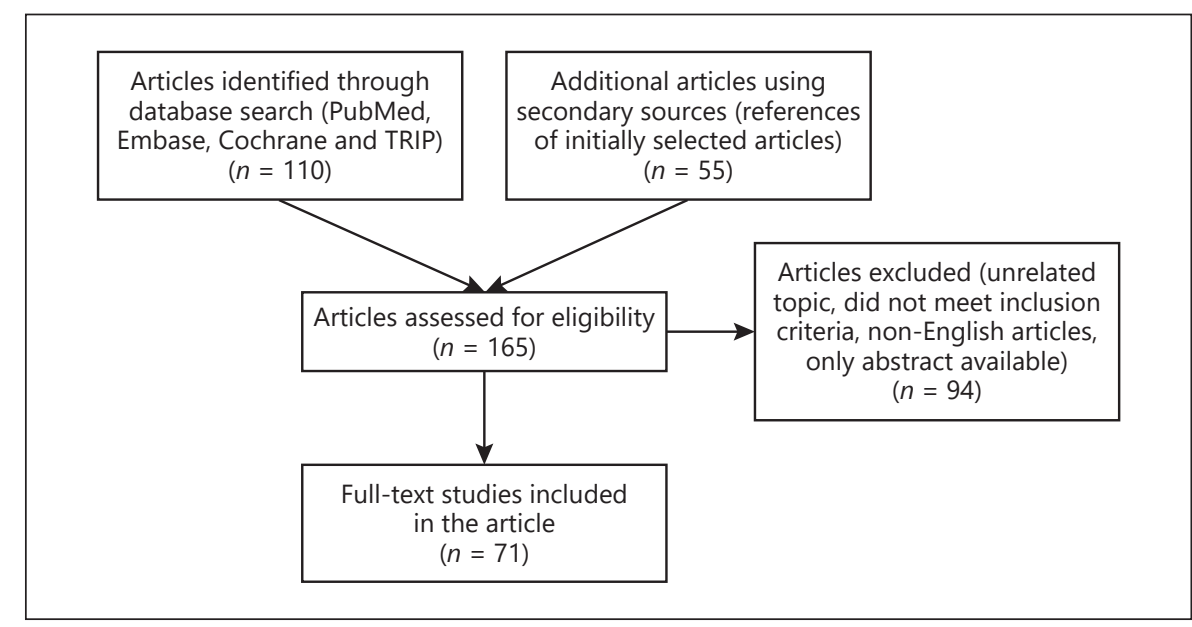
rithm of search strategy.

\section{Background (Pathophysiology of Aneurysm Formation)}

The complex mechanism of aortic aneurysm formation is known to involve infiltration of the aortic media by inflammatory cells such as macrophages and monocytes in response to aortic injury [9]. This increase in macrophages results in disrupted ECM (extracellular matrix) remodeling. ECM remodeling requires a balance between proteases and their inhibitors [9]. Proteases like matrix metalloproteinases (MMPs) have been shown to have a deleterious effect on the aorta [10]. In aneurysm disease, there has been an increase in proteases like MMPs and a depression in their inhibitory enzymes (tissue inhibitors of metalloproteinases) [10]. This causes destruction of collagen and elastin in the ECM and loss of smooth muscle cells [11]. ECM breakdown by MMPs is responsible for thinning and destruction of the normal architecture of the aortic wall, rendering it susceptible to dilation and aneurysm formation [12, 13]. (Fig. 3) [10].

Studies have shown an increase in MMP enzymes in aneurysmal tissue $[10,13]$. MMPs belong to a family of zinc- and calcium-dependent endopeptidases that play a major role in degradation of the connective tissue [14]. The regulation of MMPs is very stringent, with activation occurring at several levels of gene expression via activation of promoters and inhibitors, while inhibition is predominantly effected by tissue inhibitors of metalloproteinases $[14,15]$. Twenty-six different MMP types have been identified and classified on the basis of their specificity [16]. Amongst these, MMP-2 and MMP-9, also known as gelatinase $A$ and $\mathrm{B}$, respectively, and MMP-3 are mainly responsible for degradation of elastin and collagen

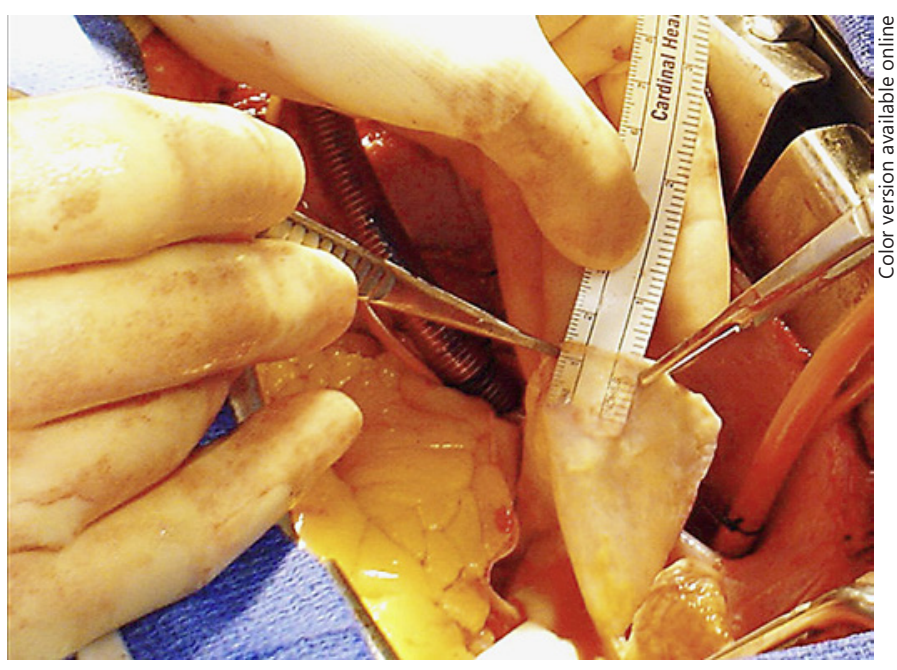

Fig. 3. Thinning of the ascending aorta, which shows the writing on the ruler through it. Reprinted with permission from Elefteriades [10].

upon proteolytic activation $[11,17]$. Increased levels of MMP-2, MMP-3 (29.6 and 142.4\% higher in TAA vs. controls, respectively) [11], MMP-1, -2 and -9 have been seen in TAA, in dissection [13], and in AAA [18]. Inflammatory cytokines like IL- $1 \beta$ and TNF- $\alpha$ have been shown to increase MMP-2 [11]. AGEs (advanced glycation end products) are a group of complex compounds formed by nonenzymatic glycation of proteins [11]. When AGE interacts with its receptor (RAGE), this results in activation of cytokines like IL-1 $\beta$, IL- 6 and TNF- $\alpha$, thus forming reactive oxygen species (ROS). This in turn increases MMPs, contributing further to aortic aneurysm forma- 
Fig. 4. The fibrinolytic pathway. PAI-1, plasminogen activator inhibitor-1; tPA, tissue plasminogen activator; uPA, urokinase plasminogen activator; MMP-3, matrix metalloproteinase- 3 .

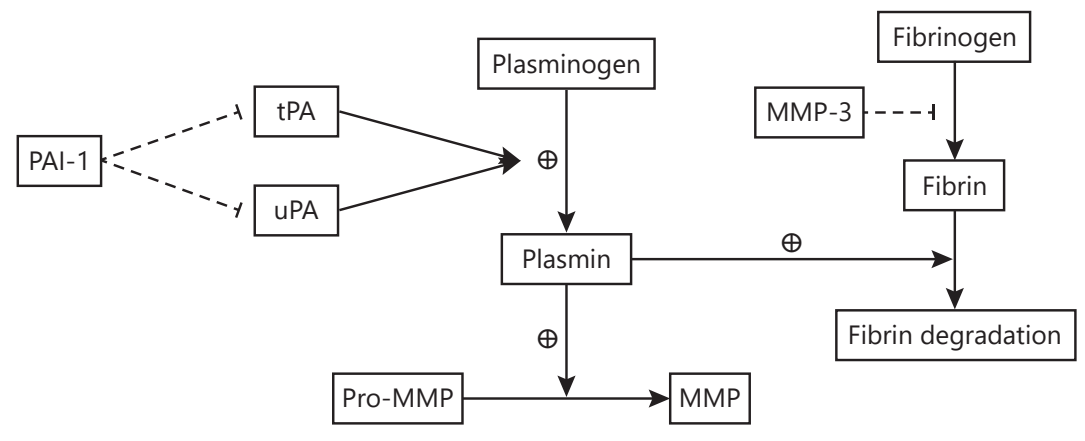

tion [11]. Serum levels of AGE in TAA patients were found to be 6.3 times higher, compared to a control group [11]. Hyperglycemia leads to production of ROS and oxidative stress in diabetes. These inflammatory reactions are aggravated by the action of AGEs on RAGEs. Thus, diabetes would be expected to be a risk factor for the development of aortic aneurysms [19].

Plasmin, an important enzyme in the fibrinolytic pathway, degrades fibrin and converts latent MMPs into active MMPs [20,21]. Studies have associated the fibrinolytic pathway (Fig. 4) with aortic aneurysm [22]. In the fibrinolytic pathway, plasmin degrades fibrin with the help of tissue plasminogen activator and urokinase plasminogen activator, thus forming fibrin degradation products [20]. Plasmin also activates MMPs, which in turn increase proteolysis in the aortic wall, further contributing to aneurysm formation [20]. An increase in plasminogen activator, which is responsible for accelerating the conversion of plasminogen to plasmin in the fibrinolytic pathway, has been seen in patients with AAA, along with an increase in plasmin $[22,23]$. Plasminogen activator inhibitor-1 inhibits tissue and urokinase plasminogen activators, thereby reducing the conversion of plasminogen to plasmin and decreasing the activation of MMPs, which in turn results in reduced inflammation, structural degradation and aneurysm formation. Disturbances in these complex regulatory enzymatic processes are an important component of the causation of TAA and AAA.

\section{Potential Mechanisms for Protection in Diabetes}

Many studies have analyzed potential mechanisms for the protective association between diabetes and aortic aneurysm (Table 1). Findings are as follows:

\section{Wall Stress}

Wall stress is said to be greater in the aorta than other arteries, with men having higher wall stress than women [24]. An imbalance between wall stress and the intrinsic strength of the aortic wall is proposed to be the cause of aortic dilation and is also related to initiation of aneurysm dissection and rupture [7]. This was demonstrated by biaxial mechanical stretching of human aortic wall samples, permitting construction of mathematical models for rupture and dissection (Fig. 5a, b) [25-27]. An increased diameter of the aorta in an aneurysm causes decreased compliance and distensibility of the aortic wall, rendering it rigid [10]. This causes more of the force of cardiac contraction to be applied on the rigid aorta, thus increasing wall stress [10].

In two recent studies looking at the interaction between diabetes and aneurysm, the law of Laplace was used to measure wall stress. Lumen diameter (LD) and intimal medial thickness (IMT) were entered into the equation $[4,7]$ :

$$
\text { Wall stress }=\frac{D B P \times L D / 2}{I M T}
$$

with DBP, diastolic blood pressure.

(Note that a thicker aorta, represented by IMT, will decrease wall stress.)

Lumen diameter in the abdominal aorta was shown to increase with age between 25 and 70 years in both males and females, from 13.3 to $17.3 \mathrm{~mm}$ [7]. Also, men were found to be more prone to increases in wall stress with advancing age, making the aorta more vulnerable [7].

Aortic IMT and wall stress in the diabetic and nondiabetic groups have been studied and compared [4]. Results showed a $22 \%$ increase in IMT in diabetics versus the control group and a resulting $20 \%$ decrease in wall stress in diabetics versus a control group (Fig. 6a, b) [4]. The thick- 
Table 1. Compilation of data regarding the role of diabetes in aortic aneurysm (AA)

\begin{tabular}{|c|c|c|c|c|c|c|c|c|}
\hline & Author & Patients, $n$ & DM type & Method & Protective effect of diabetes & Other effects & Aorta studied & Comments \\
\hline \multicolumn{9}{|c|}{ Observational studies } \\
\hline 1 & $\begin{array}{l}\text { Astrand } \\
{[4]}\end{array}$ & $\begin{array}{l}39 \text { diabetics } \\
46 \text { controls }\end{array}$ & Type 1 & $\begin{array}{l}\text { Wall stress in abdominal } \\
\text { aorta }\end{array}$ & $\downarrow$ aortic wall stress & Larger IMT & Abdominal aorta & $\begin{array}{l}\text { Brachial pressure measured } \\
\text { instead of AA pressure }\end{array}$ \\
\hline 2 & $\begin{array}{l}\text { Theivacumar } \\
\text { [34] }\end{array}$ & $\begin{array}{l}\text { Total }=2,062 \\
238 \text { diabetics } \\
(11.54 \%)\end{array}$ & $\begin{array}{l}\text { Not } \\
\text { specified }\end{array}$ & Hospital records & $\downarrow$ aneurysm rupture & $\begin{array}{l}\text { Rupture in younger } \\
\text { nondiabetics } \\
\text { ( }<65 \text { years })\end{array}$ & $\begin{array}{l}\text { Thoracic and } \\
\text { abdominal aorta }\end{array}$ & $\begin{array}{l}\text { No range of blood glucose } \\
\text { in diabetic patients }\end{array}$ \\
\hline 3 & $\begin{array}{l}\text { Jimenez-Trujillo } \\
\text { [40] }\end{array}$ & $\begin{array}{l}\text { Total }=11,594 \\
1,103 \text { diabetics } \\
(9.51 \%)\end{array}$ & Type 2 & $\begin{array}{l}\text { TAAD data from the } \\
\text { health database }\end{array}$ & $\uparrow$ hospitalization & $\downarrow$ in-hospital mortality & Thoracic aorta & \\
\hline 4 & $\begin{array}{l}\text { Prakash } \\
{[41]}\end{array}$ & $\begin{array}{l}\text { Total }=8,877 \\
13 \% \text { diabetic }\end{array}$ & $\begin{array}{l}\text { Not } \\
\text { specified }\end{array}$ & $\begin{array}{l}\text { TAAD discharge data } \\
\text { in DM }\end{array}$ & $\begin{array}{l}\downarrow \text { TAAD } \\
\text { hospitalization }\end{array}$ & $\begin{array}{l}\downarrow \mathrm{MMP}, \downarrow \text { aortic } \\
\text { inflammation }\end{array}$ & Thoracic aorta & \\
\hline 5 & $\begin{array}{l}\text { De Rango } \\
{[49]}\end{array}$ & $\begin{array}{l}\text { Total }=360 \\
49 \text { diabetics }(13.6 \%)\end{array}$ & $\begin{array}{l}\text { Type } 1 \text { and } \\
2\end{array}$ & CAESAR trial & $\uparrow$ protection in males & $\begin{array}{l}\text { Advance diabetes } \\
\text { reduces hazards }\end{array}$ & $\begin{array}{l}\text { Thoracic and } \\
\text { abdominal aorta }\end{array}$ & $\begin{array}{l}\text { Unclear comparison between } \\
\text { diabetics and nondiabetics }\end{array}$ \\
\hline 6 & $\begin{array}{l}\text { Tsai } \\
{[36]}\end{array}$ & $\begin{array}{l}160,391 \text { diabetics } \\
646,710 \text { controls }\end{array}$ & Type 2 & National insurance data & Slower growth rate of AAA & $\uparrow$ cardiovascular risk & Abdominal aorta & $\begin{array}{l}\text { Unable to define severity level } \\
\text { of DM }\end{array}$ \\
\hline \multicolumn{9}{|c|}{ Literature reviews } \\
\hline 7 & $\begin{array}{l}\text { De Rango } \\
{[46]}\end{array}$ & & $\begin{array}{l}\text { Not } \\
\text { specified }\end{array}$ & Literature review & $\begin{array}{l}\text { Reduced } \\
\text { AAA enlargement in diabetics }\end{array}$ & Excess vascular matrix & Abdominal aorta & $\begin{array}{l}\text { Extreme variability in number } \\
\text { of patients }\end{array}$ \\
\hline 8 & $\begin{array}{l}\text { Takagi } \\
{[42]}\end{array}$ & & $\begin{array}{l}\text { Not } \\
\text { specified }\end{array}$ & Web-based search & $\downarrow$ TAA/TAD growth & $\begin{array}{l}\text { TAD protects against } \\
\text { DM }\end{array}$ & Thoracic aorta & \\
\hline 9 & $\begin{array}{l}\text { Golledge } \\
{[47]}\end{array}$ & & $\begin{array}{l}\text { Not } \\
\text { specified }\end{array}$ & Web-based search & $\downarrow$ risk of rupture & & Abdominal aorta & \\
\hline 10 & $\begin{array}{l}\text { Shantikumar } \\
{[18]}\end{array}$ & & $\begin{array}{l}\text { Not } \\
\text { specified }\end{array}$ & Literature review & $\begin{array}{l}\text { ACEI, } \\
\text { statins, rosiglitazone } \\
\text { are protective }\end{array}$ & $\downarrow$ MMP-2 and MMP-9 & Abdominal aorta & \\
\hline \multicolumn{9}{|c|}{ Animal studies } \\
\hline 11 & $\begin{array}{l}\text { Miyama } \\
{[50]}\end{array}$ & & & $\begin{array}{l}\text { Hyperglycemia/AAA } \\
\text { induced in mice }\end{array}$ & $\begin{array}{l}\downarrow \text { neovascularization } \\
\downarrow \text { macrophage infiltrate }\end{array}$ & $\begin{array}{l}\downarrow \text { MMP } \\
\uparrow \text { elastin }\end{array}$ & Abdominal aorta & \\
\hline 12 & $\begin{array}{l}\text { Dua } \\
{[22]}\end{array}$ & & & $\begin{array}{l}\text { Hyperglycemia/AAA } \\
\text { induced in mice }\end{array}$ & $\begin{array}{l}\downarrow \text { AAA diameter } \\
\uparrow \text { PAI- } 1\end{array}$ & $\downarrow$ plasmin $(\mathrm{PAP})$ & Abdominal aorta & \\
\hline
\end{tabular}

DM, diabetes mellitus; IMT, intima-media thickness; TAAD, thoracic aortic aneurysm and dissection; MMP, matrix metalloproteinase; AAA, abdominal aortic aneurysm; TAD, thoracic aortic dissection; ACEI angiotensin-converting enzyme inhibitor; PAI-1, plasminogen activator inhibitor-1; PAP, plasmin- $\alpha_{2}$-antiplasmin complex.

er aortic wall in diabetes exerts a strong potential protective factor against aneurysm disease, since the thicker wall reduces wall stress (by LaPlace's law) [4].

Interestingly, tensile wall stress has been shown to act as a stimulus for increased connective tissue production and further (protective) wall thickening [28].

\section{Matrix Metalloproteinases}

Secretion of MMPs occurs via endothelial cells and macrophages [15]. An extracellular pathologic feature of diabetes is a thickened basement membrane due to deposition of excess collagen and fibronectin. This alteration of the basement membrane is effected by MMPs and tissue inhibitors of metalloproteinases[29]. The process of collagen loss and thinning of the aortic wall in aneurysm is slowed in patients with DM [18]. Reduced levels of MMP-2 and -9 have been observed in diabetics with AAA $[18,30]$. A study was conducted to investigate the activity and presence of MMPs in AAA patients with and without diabetes [29]. A reduction was found in concentrations of
MMP-1, MMP-2 and MMP-9 in diabetics. This decrease is thought responsible for vascular remodeling causing thickening of the aortic wall and decelerated matrix loss in the diabetic aneurysm patient [18].

Experimental studies using human umbilical vein endothelial cells exposed to varying levels of glucose have shown an association between blood glucose and MMP activity. These experiments showed an increase in MMP activity with increasing blood glucose levels, especially MMP-1, MMP-2 and MMP-9 [15]. However, this would mitigate against any protective role that DM could have against aortic aneurysm.

\section{Advanced Glycation End Products}

Glycation of ECM due to high levels of glucose increases AGEs in diabetics [18, 31]. AGE is responsible for forming covalent cross-links within the ECM, especially between elastin and collagen in the vessel wall [32]. These effects stiffen the aortic wall and resist proteolysis, therefore protecting against aneurysm $[18,30,33]$. Contrary to 


\section{The biomechanical properties of aortic tissues}

1. Planar biaxial test
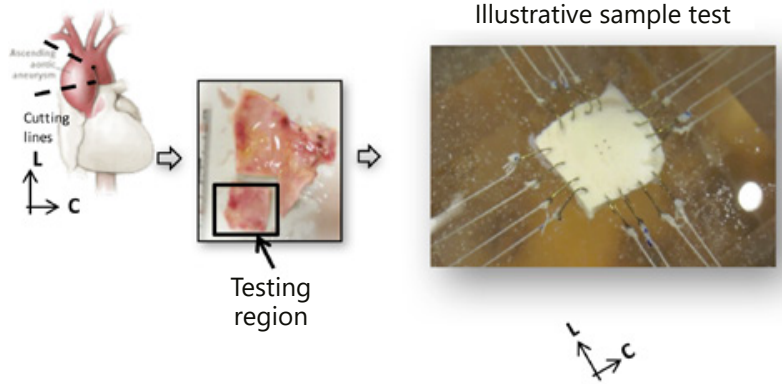

Biaxial system

- Two load cells for load measurements

- Four markers glued to the tissue surface for

deformation measurements

- Load and deformation measurements are synchronized

Sample preparation

- Square specimen: $20 \times 20 \mathrm{~mm}$

- Four hooks anchored on each tissue edge

- Suture lines extend from hooks to the motor arm and load cell

Biaxial testing results of one aneurysmal tissue sample
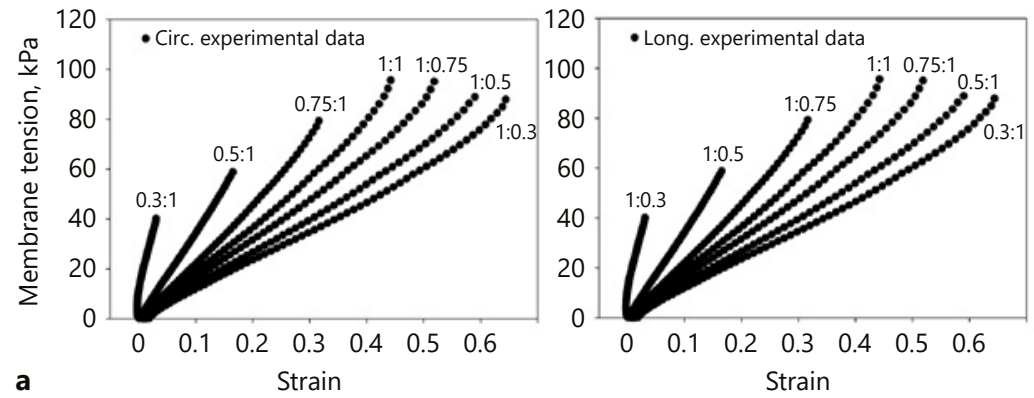

Multidirectional responses
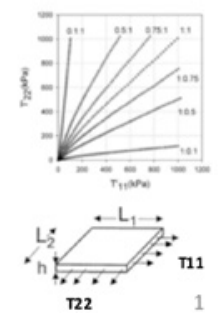

Predictive modeling using data of one patient

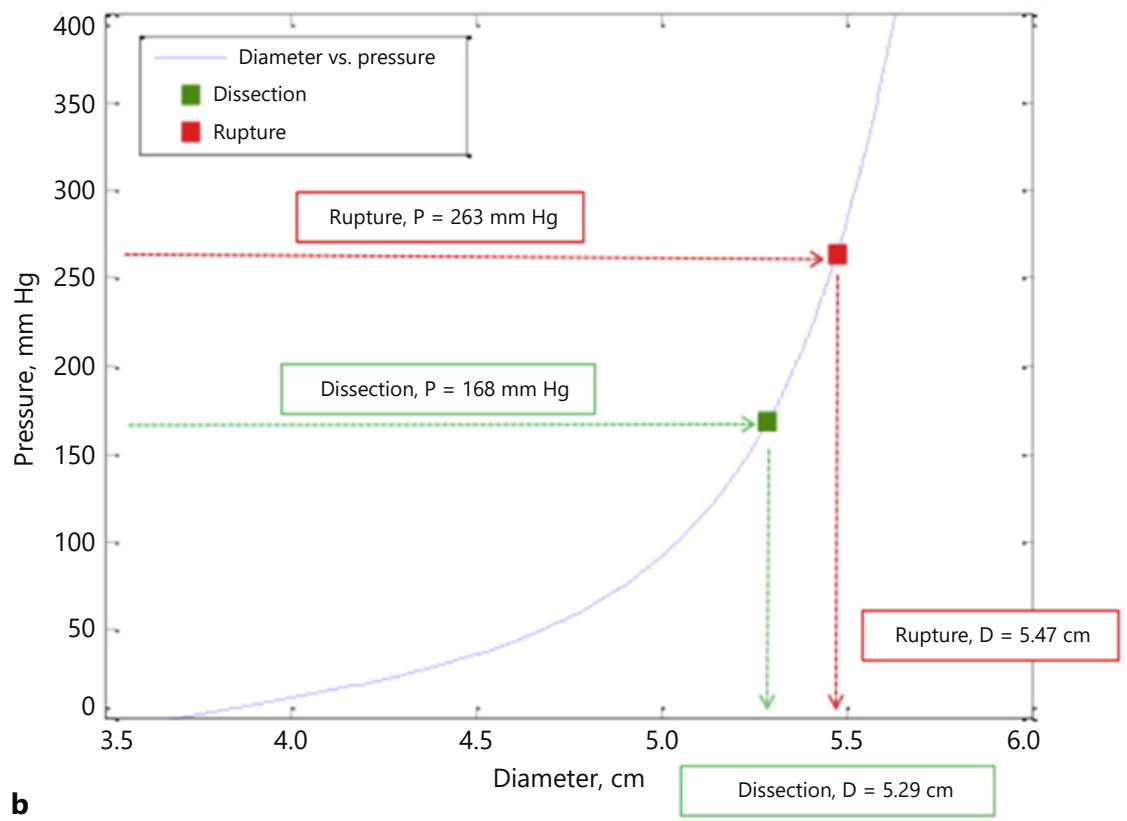

Fig. 5. a Biaxial testing was performed on ascending aortic tissue, and the stress-strain responses were calculated. Reprinted with permission from Martin et al. [25], Pham et al. [26] and Elefteriades et al. [27]. b Engineering analysis combining tensile strength from uniaxial testing with mathematic modeling from biaxial testing permits "prediction" of exact sizes at which rupture and dissection would have occurred. Reprinted with permission from Elefteriades et al. [27]. 
Fig. 6. a Abdominal aorta intima-media thickness (IMT) in healthy individuals versus diabetics. The multiple circles represent individual patients, and the solid line is the mean value. Note increased aortic IMT in diabetics. Reprinted with permission from Astrand et al. [4]. b Abdominal aortic wall stress in healthy individuals versus diabetics. The multiple circles represent individual patients, and the solid line is the mean value. Reduced wall stress is noted in diabetics. Reprinted with permission from Astrand et al. [4].

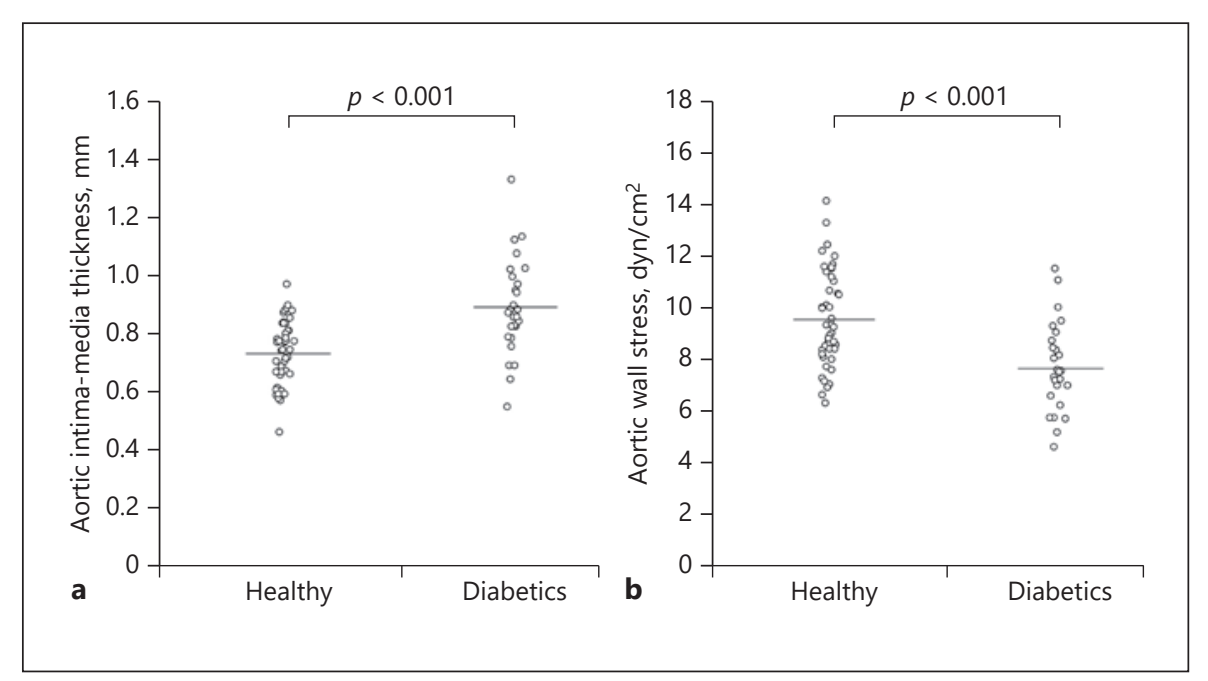

this, however, as mentioned above, other studies [11] have suggested that an increase in AGE and RAGE upregulates inflammatory mediators, encouraging formation of an aortic aneurysm [11]. In such complex pathophysiologic environments as the aneurysmal aortic wall, not all data can be expected to be consistently concordant.

\section{Epidemiologic Impact of Diabetes on Aneurysm Disease}

Diabetes is thought to exert a protective role in both TAA and AAA. There are two important studies that analyzed the relationship of diabetes with both TAA and AAA.

Diabetic and nondiabetic patients with TAA, TAAA (thoracoabdominal aortic aneurysm) or AAA were included in the first study [34]. Many variables, such as rupture, age at rupture and mortality, were studied in the patients. In TAA rupture, it was observed that $3.1 \%$ of ruptured TAAs were diabetic whereas $12.1 \%$ of nonruptured TAAs were diabetic [34]. In TAAA rupture, none of the ruptured TAAAs were diabetic, whereas $11.2 \%$ of nonruptured TAAAs were diabetic [34]. In AAA rupture, $6.4 \%$ of ruptured AAAs were diabetic, whereas $12.4 \%$ of nonruptured AAAs were diabetic. As for age at rupture, not even a single diabetic under the age of 65 years suffered from a ruptured aneurysm, while $15 \%$ of nondiabetics developed rupture under 65 years. The median age of aneurysm rupture in both diabetic and nondiabetic patients was 74 years [34]. Concerning mortality, the percentage of patients dying due to an aneurysm rupture was
$23.9 \%$ in nondiabetics and $8.8 \%$ in diabetic patients [34]. The growth rate of AAA in diabetic patients was seen to be much slower than that of nondiabetics $[34,35]$. This is thought to be due to reduced MMP production and increased collagen cross-linking associated with hyperglycemia, which in turn also resists proteolysis and apoptosis in the aortic wall, specifically in the abdominal aorta [34, 35].

A more recent study (2015) looked at how the severity of diabetes affected TAA and AAA with or without rupture [36]. Aneurysm patients were divided into 2 groups: with type $2 \mathrm{DM}$ and without DM. Hazard ratios were calculated to assess the association. Results showed an overall $15 \%$ reduction in incidence of TAA and AAA in the type $2 \mathrm{DM}$ group [36]. Reduced occurrence of ruptured TAA and unruptured AAA was seen in type $2 \mathrm{DM}$ patients, with an adjusted hazard ratio of 0.50 and 0.53 , respectively [36]. All these data show evidence of a protective effect of DM.

This study also compared risks between men and women, showing a reduced protective effect of diabetes in women with TAA or AAA compared to men. This could be due to estrogen, which possibly plays an important role in worsening the prognosis in women [36]. However, this is a controversial scenario because other studies have suggested a decrease in destruction of the aortic wall and lower levels of MMP in the presence of estrogen thus lowering the incidence of AAA in women compared to men [37]. However, those women who develop an AAA have a poorer prognosis compared to men $[37,38]$. The potential protective role of DM in women, accordingly, appears more muted. 


\section{Specific Impact of Diabetes on TAA}

TAA is a potentially lethal disease, which is often asymptomatic until a devastating fatal rupture or dissection occurs [12, 39]. About 10.4/100,000 people develop a TAA per year in the USA [39]. There are several studies that have studied the association of DM with TAA or thoracic aortic disease.

A study conducted in Spain used the national hospital discharge data to analyze various outcomes including discharge rate, length of hospital stay and in-hospital mortality in thoracic aortic aneurysm and dissection (TAAD). This study found a reduced length of hospitalization and reduced mortality in the diabetic patients [40].

A 2012 study used data from a nationwide inpatient sample of hospitalized patients to determine associations between DM and TAAD [41]. The authors found increased TAAD hospitalizations among nondiabetics compared to diabetics [41]. The incidence of TAAD in diabetics was lower than in nondiabetics and this inverse association was stronger in those with chronic diabetes complications [41]. This implies that the severity of hyperglycemia may play a potential protective role in aneurysm patients.

A meta-analysis and literature search carried out to study the association between DM and TAA/TAD showed a decrease in incidence of TAA/TAD among diabetics and also a reduced rate of aneurysm rupture [42]. As well, patients with DM demonstrated a slower aneurysm growth rate compared to non-DM patients [42].

\section{Specific Impact of Diabetes on AAA}

AAA is a localized and full thickness dilation of the abdominal aorta due to weakening of the aortic wall [43, 44]. AAA and atherosclerosis share many common risk factors, including age, smoking, hypertension and hypercholesterolemia [45].

A number of literature searches have been undertaken to study the impact of DM on incidence [46], prevalence $[18,46]$, growth rate, aortic diameter and operative mortality of AAA [30, 33, 43, 47]. Results showed a lower incidence and prevalence of AAA in diabetics $[30,33,43$, $46,47]$. This was more evident in men than women [46]. Studies have confirmed that aneurysms are smaller in diabetics than nondiabetics, suggesting that DM may potentially be protective from the early stages of AAA [18]. One meta-analysis found that the prevalence of DM in AAA patients was only $6-14 \%$ and in controls without

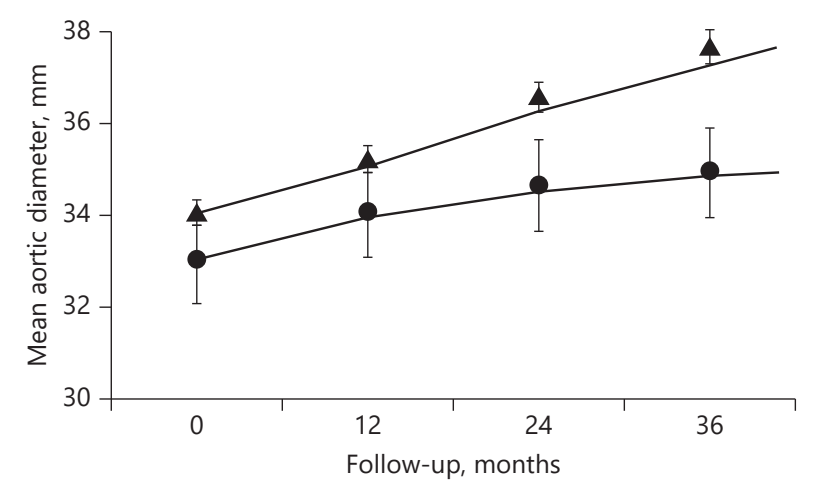

Fig. 7. Mean abdominal aortic diameter $(\mathrm{mm})$ during 3 years of follow-up for patients with and without diabetes. Reprinted with permission from Golledge et al. [31].

AAA ranged from 17 to $36 \%[18,30,43]$. The growth rate and rupture rates of AAA in diabetics were also lower compared to nondiabetic patients [30, 33, 46, 47]. 12,203 men were included in the screening for AAA, which showed that the median aortic diameter was slightly but significantly smaller in the diabetic males versus nondiabetic males ( $21.3 \pm 3.9$ vs. $21.6 \pm 3.8 \mathrm{~mm}, p<0.0001)$ [48]. However, as might be expected, when surgery was needed for the AAA, a higher rate of complications was seen among diabetics [46].

Golledge et al. [31] studied the impact of DM on AAA expansion and the effect of glycation on monocyte-matrix interactions. A mean increase in aortic diameter was $1.88 \pm 2.37$ and $3.60 \pm 3.49 \mathrm{~mm}$ over 3 years of follow-up in patients with and without diabetes, respectively ( $p=$ 0.02). (Fig. 7) [31]. When the authors examined the effect of glycation on secretion of MMP-2, MMP-9 and IL-6 from monocytes (by incubating monocytes with glycated collagen lattices), they found reduced secretion of MMP2, MMP-9 and IL-6 [31].

De Rango et al. [49] used data from CAESAR (Comparison of Surveillance versus Aortic Endografting for Small Aneurysm Repair) to compare diabetics and nondiabetics with small AAAs. CAESAR is a multicenter randomized trial comparing the efficacy of endovascular aortic repair versus surveillance in small AAAs. Many factors were studied, including adverse events, growth rate and type of repair. The adverse event rate did not differ significantly between diabetics (13.8\%) and nondiabetics $(11.8 \%)$. The growth rate in the 1st year of study was $0.044 \mathrm{~mm}$ in both groups. However, in the 2nd year 


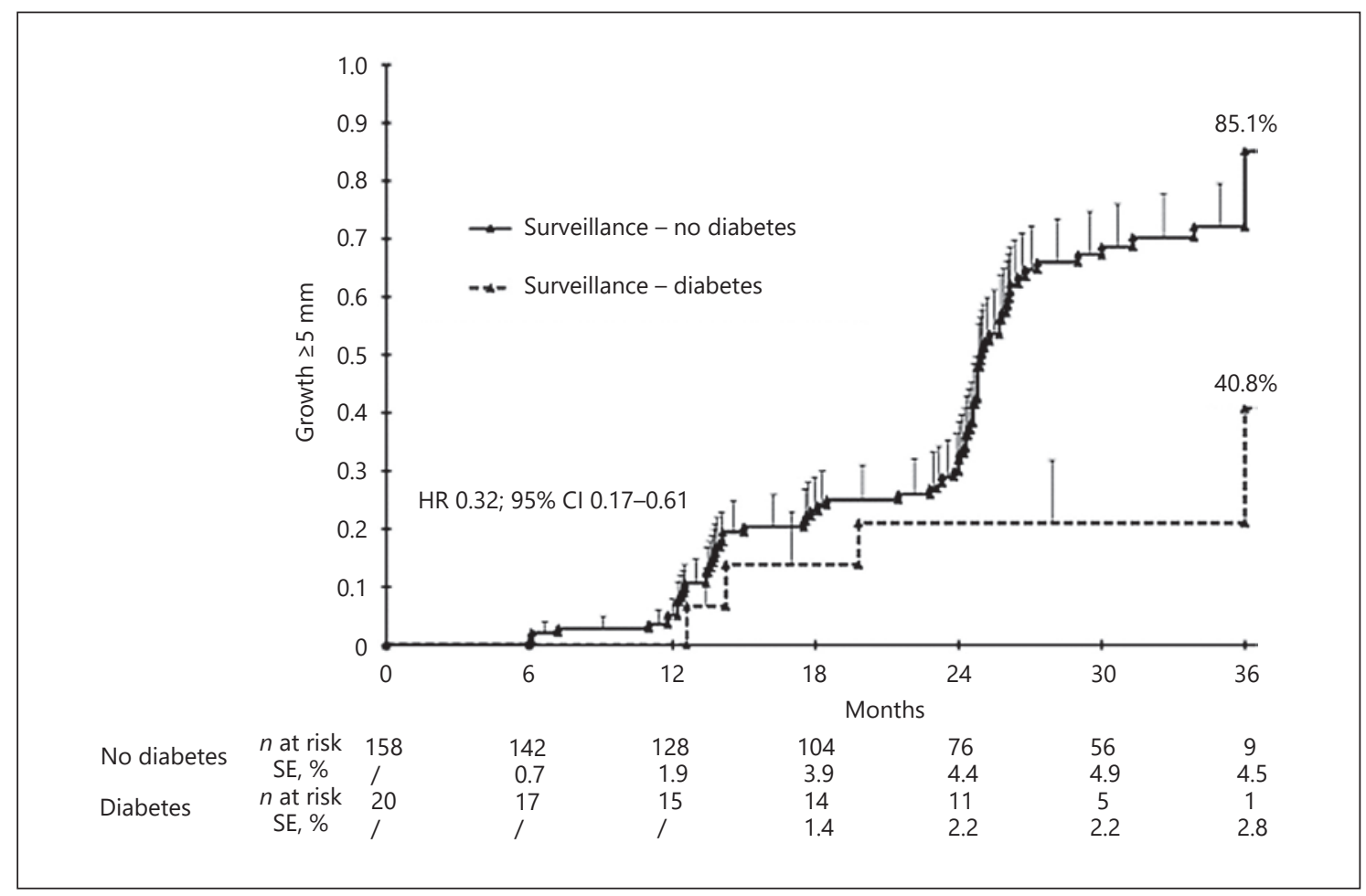

Fig. 8. Aneurysm growth rates $>5 \mathrm{~mm}$ at 36 months within the surveillance arm in diabetic and nondiabetic patients (using Kaplan-Meier analyses). CI, confidence interval; HR, hazard ratio; SE, standard error. Reprinted with permission from De Rango et al. [49].

the AAA growth rate was substantially higher in nondiabetics than in diabetics ( 0.07 vs. $0.008 \mathrm{~mm}$ ). Kaplan-Meier analysis was used to analyze the aneurysm enlargement using a cutoff of $5 \mathrm{~mm}$. Diabetic patients in the surveillance group showed a lower probability of aneurysm growth $>5 \mathrm{~mm}$ at 36 months, with a $68 \%$ risk reduction compared to nondiabetics (Fig. 8). Also, diabetics in the surveillance group demonstrated less need for endovascular aortic repair at 30 months compared to nondiabetics.

Dua et al. [22] studied the role of hyperglycemia on aortic diameter in induced AAA mouse models. Aortic diameter in DM-AAA mice was $0.92 \pm 0.02$ versus $1.08 \pm$ $0.05 \mathrm{~mm}(p<0.05)$ in nondiabetic AAA mice [22]. DMAAA mice showed an increase in plasminogen activator inhibitor-1 level (with reduced plasmin), resulting in decreased MMP-2 and MMP-9 and thus protecting against aneurysm formation (Fig. 9) [22].

Miyama et al. [50] investigated the role of hyperglycemia on aortic diameter, medial neovascularity and MMP9 level. A statistically significant reduction in aortic diameter was seen in DM-AAA mice compared to controls $(p=0.047)$. Aortic medial neovascularity has been shown to play a role in aneurysm pathogenesis via its close involvement with MMP activation in the proteolytic degradation of the aortic wall $[50,51]$. This study showed a decrease in neovessel density, macrophage infiltration and MMP-9 levels, demonstrating hyperglycemia to be protective against the formation of an aneurysm.

\section{Role of Hypoglycemic Agents on Aneurysm}

There is evidence from clinical and experimental studies that the drugs used to treat DM may protect against aortic aneurysm, both TAA and AAA. Multiple antidiabetic drugs have been studied in this regard.

\section{Role of PPAR- $\gamma$ Agonists in Aortic Aneurysm}

PPAR- $\gamma$ is the main target of the drug class of thiazolidinediones. (Drugs in this class include rosiglitazone and pioglitazone.) These antidiabetic agents exhibit anti-inflammatory effects by reducing the levels of TNF- $\alpha[52$, 53]. 


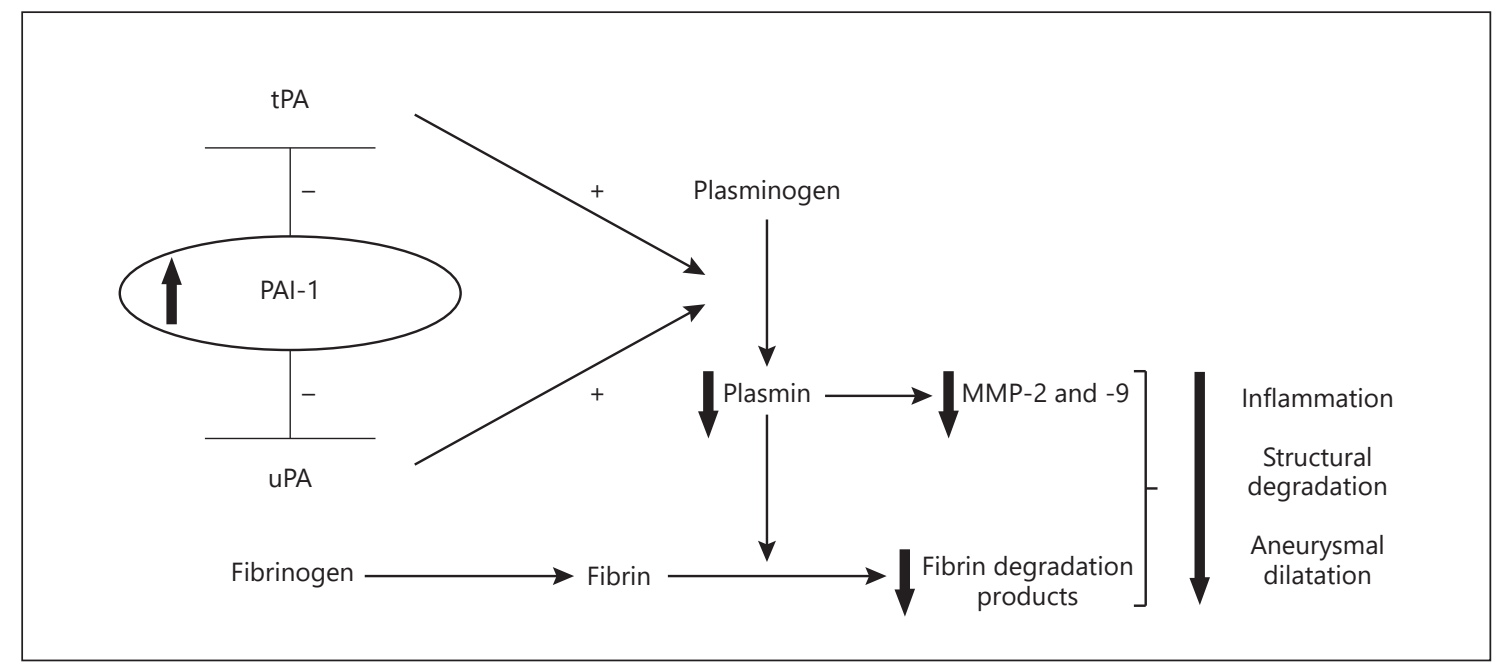

Fig. 9. The fibrinolytic pathway, in a diabetic, showing increased PAI-1 and its effect on plasmin and MMPs. PAI-1, plasminogen activator inhibitor-1; tPA, tissue plasminogen activator, alteplase; uPA, urokinase plasminogen activator; MMP, matrix metalloproteinase. Reprinted with permission from Dua et al. [22].

1 A study conducted in Japan by Motoki et al. [52] divided aneurysm patients into 2 groups: one receiving a PPAR- $\gamma$ agonist and the other a control group. The study compared aneurysm size, gene expression of adiponectin (which regulates blood glucose levels) and proteolytic and inflammatory activity including MMP2, MMP-9 and TNF- $\alpha$. There was no significant difference in aneurysm size between groups. However, gene expressions of adiponectin and MMP-2, MMP-9 and TNF- $\alpha$ were significantly reduced in the PPAR- $\gamma$ agonist group of patients, suggesting a potent anti-aneurysm effect. PPAR- $\gamma$ agonists, in addition to improving insulin sensitivity [54] and exerting anti-inflammatory effects, are also considered to be antiatherosclerotic $[55,56]$.

2 Jones et al. [57] conducted a study on aortic aneurysm in a mouse model. The mice were divided into 4 different groups. AAA was induced using angiotensin-II (Ang-II) in 3 groups, while the 4th group received saline. The 1st was a positive control group without rosiglitazone, the 2 nd received rosiglitazone before treatment, the 3rd received post-treatment rosiglitazone, and the 4 th group as mentioned above was a control which received saline. In the positive control group, $37 \%$ of mice died of aortic rupture and 53\% developed an aneurysm. Pretreatment with rosiglitazone showed a $23 \%$ reduction in aneurysm formation. Post-treatment with rosiglitazone showed a $20 \%$ reduction in aneurysm formation and abolished death caused by rupture. Rosiglitazone treatment, both pre and post, increased collagen production in the Ang-II-induced aneurysm mice and also reduced inflammatory mediators like TNF- $\alpha$ and IL-6. Contradictory to other studies, the mice showed no change in MMP-2 or MMP-9 levels with either pre- or post-treatment with rosiglitazone. Therefore, rosiglitazone was shown to reduce inflammation and make the aortic wall thicker by increasing collagen production. Rosiglitazone prevented rupture and death.

3 Pirianov et al. [58] looked at the protective role of rosiglitazone on induced aneurysm animal models by dividing them into 2 groups: one a positive control mouse model with induced aneurysm but without rosiglitazone, and the second a mouse model with induced aneurysm but with administered rosiglitazone. In the control group, 53\% developed aneurysms and $37 \%$ died of aneurysm rupture. In the rosiglitazone group, rupture was completely abolished, and aneurysm formation was reduced to $23 \%$. Rosiglitazone has also been shown to inhibit Ang-II, which increases the formation of an experimental aneurysm by several means, two of those involving c-Jun N-terminal kinase (JNK) and TLR4 [58]. JNK plays a critical role in extrinsic and intrinsic apoptotic pathways by activating apoptotic signals via proapoptotic genes [59]. Increased levels of JNK were observed in the experimental aneurysm mouse models [58]. However, administration of rosiglitazone in mice inhibited Ang-II-me- 
Fig. 10. Abdominal aortic aneurysm (AAA) enlargement based on demographic and environmental risk factors. Diabetic patients not receiving oral hypoglycemic therapy showed a median rate of AAA enlargement of $1.5 \mathrm{~mm} /$ year. Likelihood ratio test, $0.05<{ }^{\#} p<0.1,{ }^{*} p<0.05$ and ${ }^{* *} p<$ 0.01. ACE, angiotensin-converting enzyme; $\mathrm{ARB}$, angiotensin II type 1 receptor blocker; BMI, body mass index; OR, odds ratio. Reprinted with permission from $\mathrm{Fu}$ jimura et al. [63].

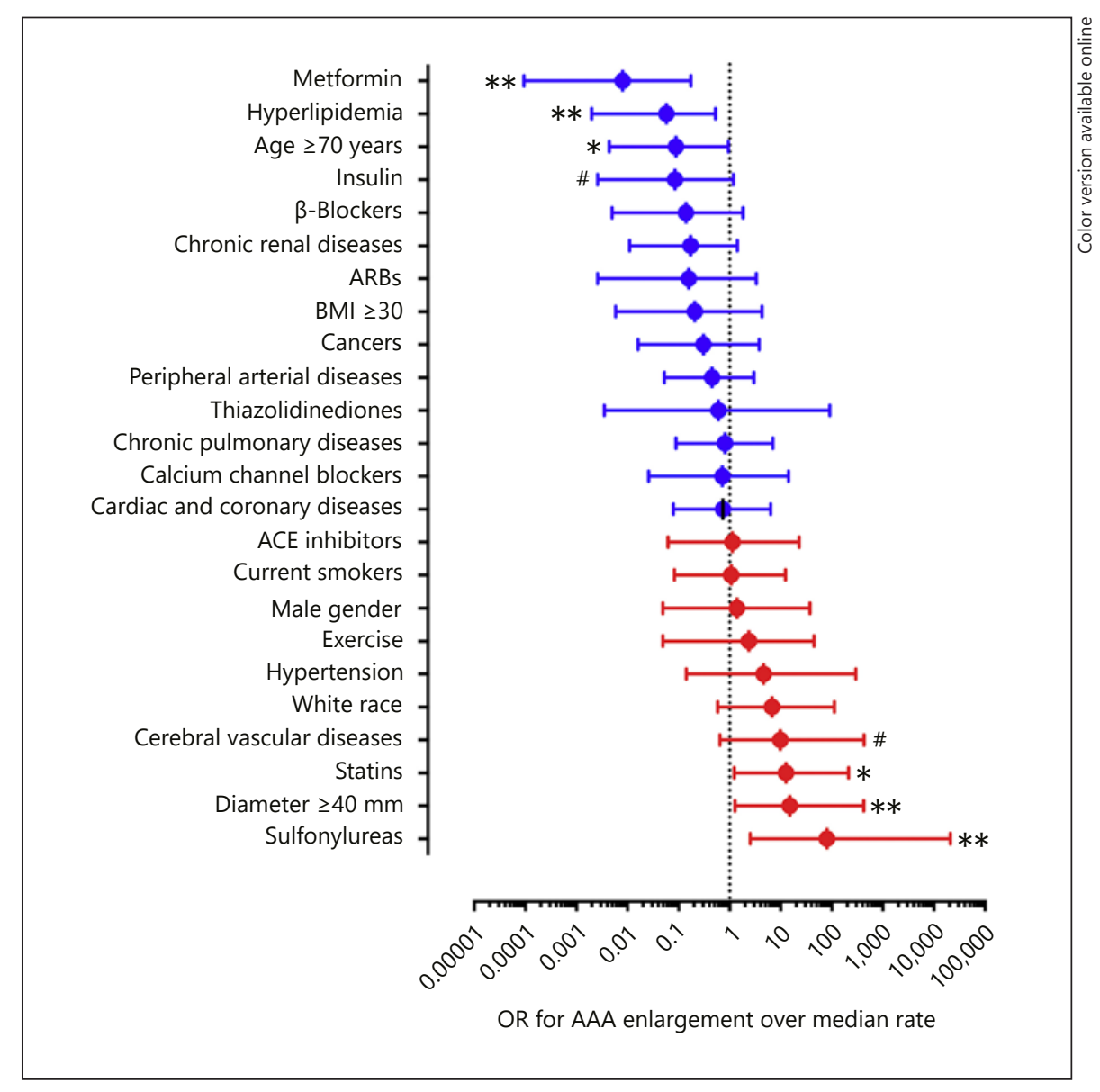

diated activation of JNK, thereby reducing the formation of aneurysms. Rosiglitazone was also found to reduce the proinflammatory mediators which are responsible for the formation of AAA, thus demonstrating that the antidiabetic rosiglitazone may play an additional potential protective role in aneurysm formation [58].

\section{Role of Metformin in Aortic Aneurysm}

Metformin is one of the oldest prescribed drugs for diabetes. It improves hyperglycemia without increasing weight or resulting in hypoglycemia [60]. In addition to glycemic control, metformin has cardiovascular benefits and is also vasculoprotective [60-62]. Metformin potentially exerts this mechanism of action via phosphorylation of AMP-activated protein kinase (AMPK) [60]. AMPK plays an important role in metabolic regulations like glycemic control via its effect on several glucose-activated lipogenesis genes and GLUT4 transporter. Metformin also controls lipid synthesis by activation of
AMPK, which potentially inhibits the acetyl-CoA enzyme responsible for synthesis of fatty acids [60].

1 Vasamsetti et al. [61] studied the above effect of metformin on AMPK and also its role on monocyte-macrophage differentiation, which is involved in inflammatory processes. In an Ang-II-treated mouse model, an increase in phorbol myristate acetate-induced monocyte-dependent proinflammatory cytokines like IL- $1 \beta$ and TNF- $\alpha$ was observed. However, in the presence of metformin, the Ang-II-treated mice showed a reduction in proinflammatory cytokine levels, indicating the protective role of metformin in the inflammation pathway. This could be the potential role via which metformin protects diabetics against the formation of an aortic aneurysm [61].

2 Fujimura et al. [63] studied the role of metformin in induced aneurysm mice. All control mice developed aneurysm within 7 days of pancreatic porcine elastase infusion. Out of the 10 metformin-treated mice, only 4 developed AAA, and even those showed attenuated 
Fig. 11. Protection from aneurysm formation by DPP-4 inhibitors. A normal rat aorta is shown on the left. The three aortas to the right of the normal aorta underwent aneurysm induction (via application of intraluminal elastase and extraluminal calcium chloride). Group C (control) received no DPP-4 inhibitor. Group LD received a low dose of DPP-4 inhibitor. Group HD received a high dose of DPP-4 inhibitor. Note the near complete prevention of aneurysm formation by high-dose DPP-4 inhibition. Reprinted with permission from Bao et al. [66].

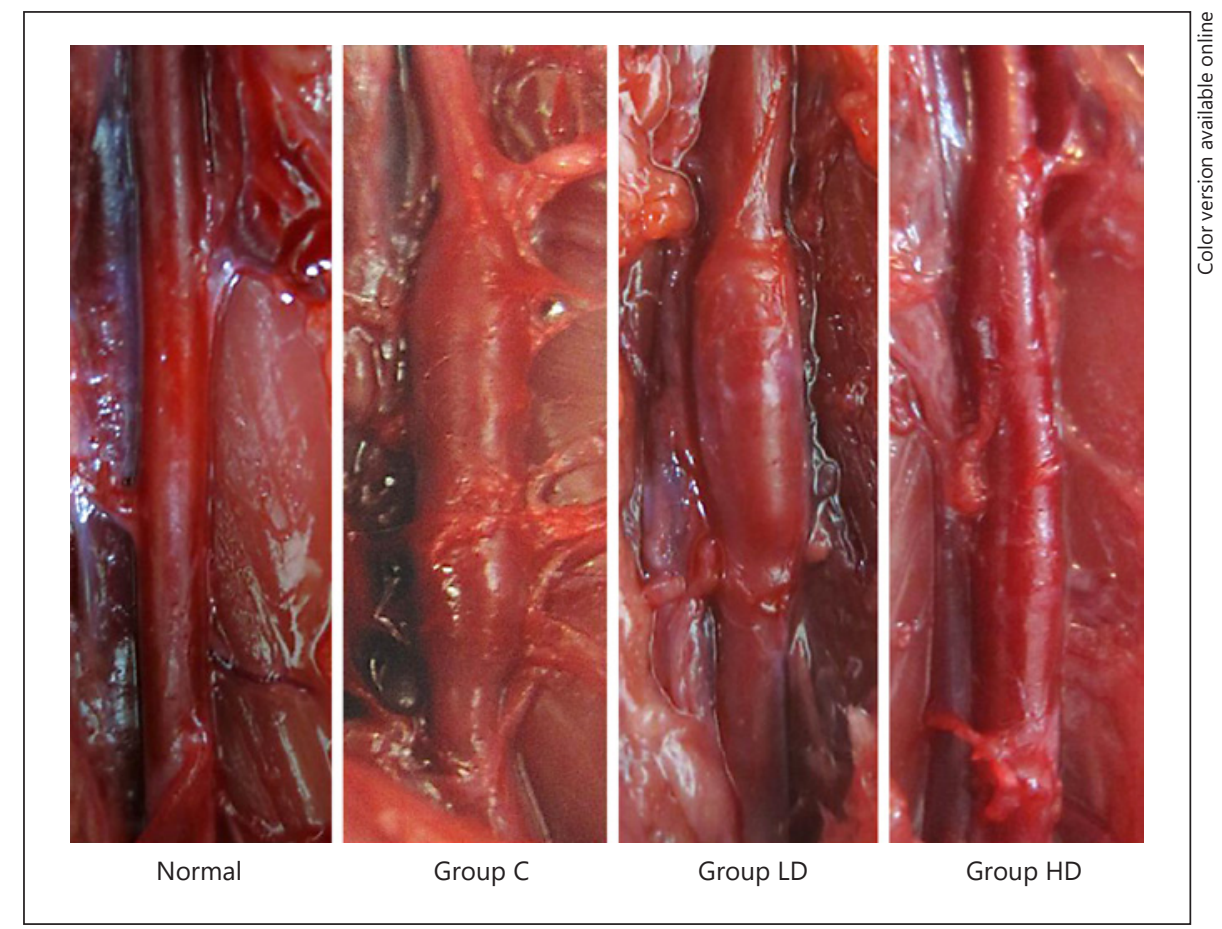

aneurysm formation. Histopathologic features of the study suggested a metformin-induced decrease in proinflammatory cells like B cells, macrophages, and CD4 and CD8 cells. A decrease in mural neovessel density was also noted in the metformin mice, as well as a reduction in elastin degradation, smooth-muscle cell depletion and aortic inflammation [63]. Elastin degradation has been shown to increase during aortic aneurysm pathogenesis along with increased smoothmuscle depletion resulting in a weakened aortic wall susceptible to rupture. These are potentially harmful pathways inhibited by using metformin, which thus appears to play a significant protective role (Fig. 10).

3 In an important clinical study on 1,697 patients, Golledge et al. [64] found that prescription of metformin was associated with reduced AAA growth (odds ratio $=0.13-0.59$ in groups followed by various protocols). This study suggests a potential clinical role for metformin in limiting AAA growth.

\section{Role of DPP-4 Inhibitor in Aortic Aneurysm}

Dipeptidyl peptidase-4 (DPP-4) inhibitors, like alogliptin and vildagliptin, belong to another class of drugs used in the treatment of DM. These act by inhibiting the proteolytic enzyme DPP-4, resulting in delayed breakdown of glucagon-like peptide- 1 and thereby enhancing glycemic control [65]. Studies have shown a beneficial effect of DPP-4 on aortic aneurysm.

1 Bao et al. [66] studied the role of orally administered alogliptin, a DPP-4 inhibitor, in preventing AAA in rats through its antioxidant effect. Rats received water and low-dose or high-dose DPP-4 inhibitors. Macroscopic findings showed significantly reduced aortic dilation in DPP-4 inhibitor-treated rats compared to water-treated rats (Fig. 11). ROS are closely associated with inflammation, cell damage and rupture, and are also reported to be intimately involved in the pathogenesis of AAA [66, 67]. ROS induces apoptosis, inflammation, loss of elastin and aortic wall thinning via matrix-degrading enzymes, thus resulting in aneurysm formation. This study showed an increase in MMP-2 and MMP-9 mRNA activity in induced aneurysm rats [66]. However, rats treated with alogliptin showed suppression of ROS activity, preventing the destruction of the aortic wall. MMP-2 and MMP-9 levels were also reduced. These findings suggest a strong protective role of DPP-4 inhibitors, particularly alogliptin, against formation of AAA.

2 Lu et al. [68] studied the role of sitagliptin, a DPP-4 inhibitor, in induced AAA animal models. The incidence of AAA in Ang-II-infused mice was 55.6\%, while sitaglitpin-treated mice had a much lower inci- 
Table 2. Role of diabetes mellitus and hypoglycemic agents in aortic aneurysm

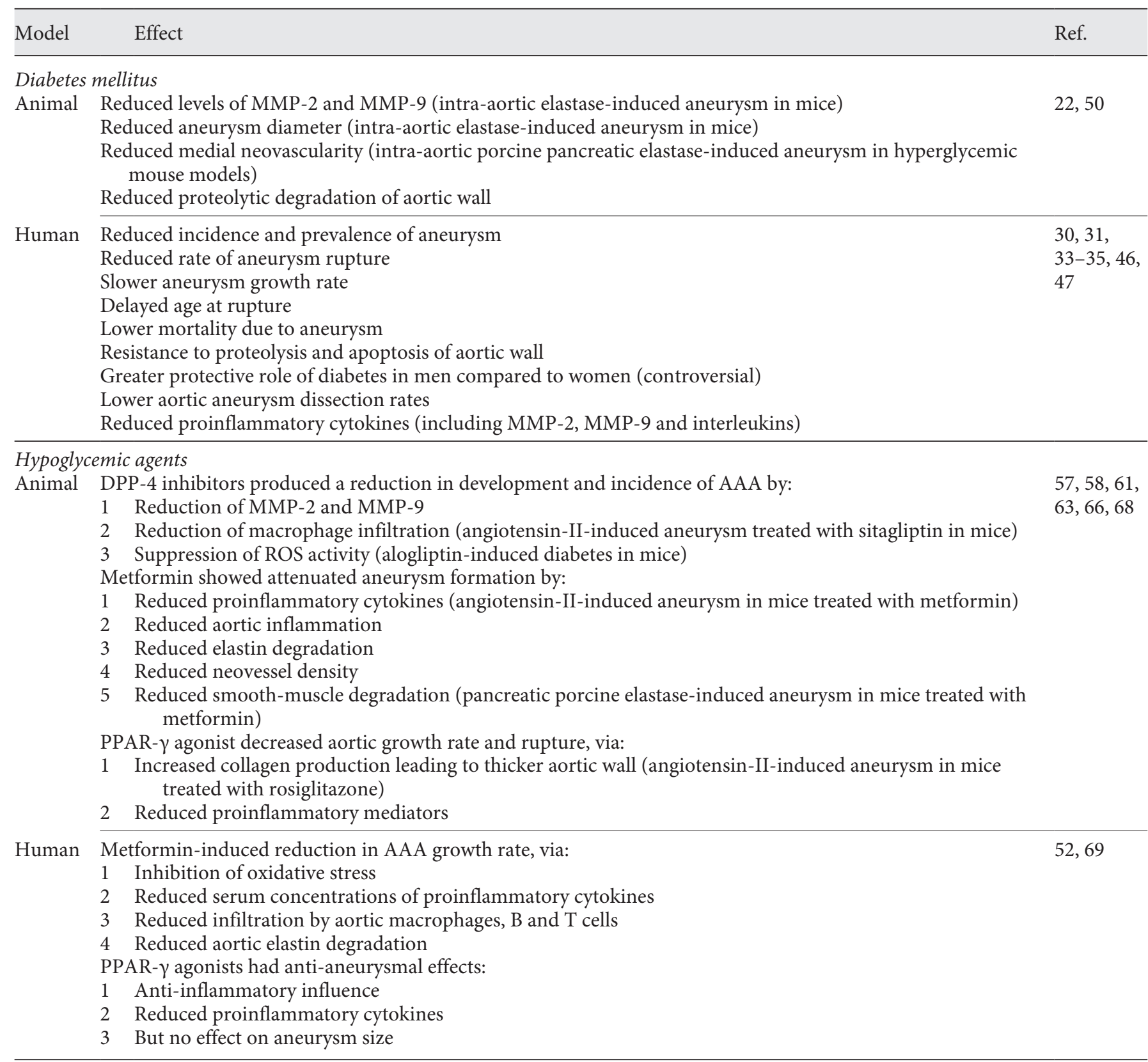

MMP, matrix metalloproteinase; DPP-4, dipeptidyl peptidase-4; ROS, reactive oxygen species; PPAR- $\gamma$, peroxisome proliferatoractivated receptor- $\gamma$; AAA, abdominal aortic aneurysm.

dence rate of $4-8 \%$. This team also studied elastin and collagen alterations using Verhoeff-Van Giesson and Masson's trichrome staining, which showed complete fiber disruption and increased matrix irregularities in Ang-II mice. On the other hand, the elastin and collagen disruptions were attenuated in sitagliptin-treat- ed mice. Sitagliptin-treated mouse models showed lower MMP-2 and MMP-9 activity, reduced apoptosis in the aortic wall and significant reduction in the macrophage infiltration. All these factors indicate a potential protective role of sitagliptin in the incidence of AAA. 


\section{Clinical Data Regarding Aneurysm Protection}

In an important study, Hsu et al. [69] conducted a case-control analysis using the National Taiwanese Database. They compared 4,468 patients with aortic aneurysm and 4,468 matched controls. Metformin-, sulfonylureaor thiazolidinedione-treated patients had a significantly lower risk of developing aortic aneurysm than those not so treated. Furthermore, the beneficial effects on aortic aneurysm for metformin and sulfonylurea were dose responsive. This study provides encouraging clinical, albeit indirect, evidence for a pharmacologic benefit to actual human patients. Also, a large meta-analysis of clinical studies of prevalence and growth rate of AAA showed a strong suppressive impact of diabetes [70].

\section{Discussion}

Aneurysms are formed by degradation and fragmentation of the aortic wall. This may be caused by a number of factors, including oxidative stress, apoptosis and inflammatory mediators, leading to loss of elastin and disorganization of collagen, and eventuating in dilatation of the aorta $[57,69]$. The aim of this review was to study the role that DM has to play in AAA and TAA. This review largely confirms the surgeon's "on the table" impression that the diabetic aorta is inimitable to growth and dissec- tion. Specifically, we find that, based on the current data, (1) DM itself protects against aortic aneurysm and dissection, and (2) medications used to treat DM appear to confer an additional, independent protection against aneurysm and dissection.

Our findings are consistent with other reviews on this topic, including those by Takagi et al. [71] and De Rango et al. [46], although our paper includes TAA as well as AAA.

It can fairly be stated that substantial evidence is accumulating that diabetes and the medications used to treat diabetes have a protective effect against formation and growth of both thoracic and abdominal aortic aneurysms. These findings are paradoxical in the sense that diabetes has always been conceived as a powerful promoter of vascular disease. A summary of the fascinating and unexpected data gleaned from animal models and human studies supporting the beneficial role of DM and hypoglycemic agents in aortic aneurysm is presented in Table 2 .

\section{Disclosure Statement}

All authors declare that there are no conflicts of interest regarding the subject matter of this paper. There are no conflicts of interest to disclose for any of the authors. There is no source of funding to declare for this paper.

\section{References}

1 Hung A, Zafar M, Mukherjee S, Tranquilli M, Scoutt LM, Elefteriades JA. Carotid intimamedia thickness provides evidence that ascending aortic aneurysm protects against systemic atherosclerosis. Cardiology. 2012; 123(2):71-7.

2 Centers for Disease Control and Prevention, Division for Heart Disease and Stroke Prevention: Data and Statistics, Factsheets.

3 Elefteriades JA, Farkas EA. Thoracic aortic aneurysm clinically pertinent controversies and uncertainties. J Am Coll Cardiol. 2010 Mar;55(9):841-57.

4 Astrand H, Rydén-Ahlgren A, Sundkvist G, Sandgren T, Länne T. Reduced aortic wall stress in diabetes mellitus. Eur J Vasc Endovasc Surg. 2007 May;33(5):592-8.

5 Zarins CK, Xu C, Glagov S. Atherosclerotic enlargement of the human abdominal aorta. Atherosclerosis. 2001 Mar;155(1):157-64.

6 Danyi P, Elefteriades JA, Jovin IS. Medical therapy of thoracic aortic aneurysms: are we there yet? Circulation. 2011 Sep;124(13): 1469-76.
7 Astrand H, Rydén-Ahlgren A, Sandgren T, Länne T. Age-related increase in wall stress of the human abdominal aorta: an in vivo study. J Vasc Surg. 2005 Nov;42(5):926-31.

8 Wolinsky H, Glagov S. Comparison of abdominal and thoracic aortic medial structure in mammals. Deviation of man from the usual pattern. Circ Res. 1969 Dec;25(6):677-86.

9 Raffort J, Lareyre F, Clément M, HassenKhodja R, Chinetti G, Mallat Z. Monocytes and macrophages in abdominal aortic aneurysm. Nat Rev Cardiol. 2017 Aug;14(8):45771.

10 Elefteriades JA. Thoracic aortic aneurysm: reading the enemy's playbook. Yale J Biol Med. 2008 Dec;81(4):175-86.

11 Prasad K, Sarkar A, Zafar MA, Shoker A, Moselhi HE, Tranquilli M, et al. Advanced Glycation End Products and its Soluble Receptors in the Pathogenesis of Thoracic Aortic Aneurysm. Aorta (Stamford). 2016 Feb; 4(1):1-10.
12 Elefteriades JA, Sang A, Kuzmik G, Hornick M. Guilt by association: paradigm for detecting a silent killer (thoracic aortic aneurysm). Open Heart. 2015 Apr;2(1):e000169.

13 Koullias GJ, Ravichandran P, Korkolis DP, Rimm DL, Elefteriades JA. Increased tissue microarray matrix metalloproteinase expression favors proteolysis in thoracic aortic aneurysms and dissections. Ann Thorac Surg. 2004;78(6):2106-10; discussion 2110-11.

14 Murphy G, Docherty AJ. The matrix metalloproteinases and their inhibitors. Am J Respir Cell Mol Biol. 1992 Aug;7(2):120-5.

15 Death AK, Fisher EJ, McGrath KC, Yue DK. High glucose alters matrix metalloproteinase expression in two key vascular cells: potential impact on atherosclerosis in diabetes. Atherosclerosis. 2003 Jun;168(2):263-9.

16 Verma RP, Hansch C. Matrix metalloproteinases (MMPs): chemical-biological functions and (Q)SARs. Bioorg Med Chem. 2007 Mar; 15(6):2223-68. 
17 Chesler NC, Ku DN, Galis ZS. Transmural pressure induces matrix-degrading activity in porcine arteries ex vivo. Am J Physiol. 1999 Nov;277(5 Pt 2):H2002-9.

18 Shantikumar S, Ajjan R, Porter KE, Scott DJ. Diabetes and the abdominal aortic aneurysm. Eur J Vasc Endovasc Surg. 2010 Feb;39(2): 200-7.

19 Volpe CM, Villar-Delfino PH, Dos Anjos PM, Nogueira-Machado JA. Cellular death, reactive oxygen species (ROS) and diabetic complications. Cell Death Dis. 2018 Jan;9(2):119.

20 Lijnen HR. Plasmin and matrix metalloproteinases in vascular remodeling. Thromb Haemost. 2001 Jul;86(1):324-33.

21 Rodríguez JA, Orbe J, Páramo JA. [Metalloproteases, vascular remodeling and atherothrombotic syndromes]. Rev Esp Cardiol. 2007 Sep;60(9):959-67.

22 Dua MM, Miyama N, Azuma J, Schultz GM, Sho M, Morser J, et al. Hyperglycemia modulates plasminogen activator inhibitor-1 expression and aortic diameter in experimental aortic aneurysm disease. Surgery. 2010 Aug; 148(2):429-35.

23 Yamazumi K, Ojiro M, Okumura H, Aikou T. An activated state of blood coagulation and fibrinolysis in patients with abdominal aortic aneurysm. Am J Surg. 1998 Apr;175(4):297301.

24 Astrand H, Sandgren T, Ahlgren AR, Länne T. Noninvasive ultrasound measurements of aortic intima-media thickness: implications for in vivo study of aortic wall stress. J Vasc Surg. 2003 Jun;37(6):1270-6.

25 Martin C, Sun W, Pham T, Elefteriades J. Predictive biomechanical analysis of ascending aortic aneurysm rupture potential. Acta Biomater. 2013 Dec;9(12):9392-400.

26 Pham T, Martin C, Elefteriades J, Sun W. Biomechanical characterization of ascending aortic aneurysm with concomitant bicuspid aortic valve and bovine aortic arch. Acta Biomater. 2013 Aug;9(8):7927-36.

27 Elefteriades JA, Habel N, Sun W, Sang AX, Kuzmik GA. The aortic wall: four questions and insights. J Thorac Cardiovasc Surg. 2013 Mar;145(3 Suppl):S130-4.

28 Leung DY, Glagov S, Mathews MB. Cyclic stretching stimulates synthesis of matrix components by arterial smooth muscle cells in vitro. Science. 1976 Feb;191(4226):475-7.

29 Portik-Dobos V, Anstadt MP, Hutchinson J, Bannan M, Ergul A. Evidence for a matrix metalloproteinase induction/activation system in arterial vasculature and decreased synthesis and activity in diabetes. Diabetes. 2002 Oct;51(10):3063-8.

30 Takagi H, Umemoto T; ALICE (All-Literature Investigation of Cardiovascular Evidence) Group. Diabetes and Abdominal Aortic Aneurysm Growth. Angiology. 2016 Jul; 67(6):513-25.
31 Golledge J, Karan M, Moran CS, Muller J, Clancy P, Dear AE, et al. Reduced expansion rate of abdominal aortic aneurysms in patients with diabetes may be related to aberrant monocyte-matrix interactions. Eur Heart J. 2008 Mar;29(5):665-72.

32 Aronson D. Cross-linking of glycated collagen in the pathogenesis of arterial and myocardial stiffening of aging and diabetes. J Hypertens. 2003 Jan;21(1):3-12.

33 Takagi H; Takuya Umemoto for the ALICE (All-Literature Investigation of Cardiovascular Evidence) Group. Association of diabetes mellitus with presence, expansion, and rupture of abdominal aortic aneurysm: "Curiouser and curiouser!" cried ALICE. Semin Vasc Surg. 2016 Mar;29(1-2):18-26.

34 Theivacumar NS, Stephenson MA, Mistry H, Valenti D. Diabetes mellitus and aortic aneurysm rupture: a favorable association? Vasc Endovascular Surg. 2014 Jan;48(1):45-50.

35 Vega de Céniga M, Gómez R, Estallo L, Rodríguez L, Baquer M, Barba A. Growth rate and associated factors in small abdominal aortic aneurysms. Eur J Vasc Endovasc Surg. 2006 Mar;31(3):231-6.

36 Tsai CL, Lin CL, Wu YY, Shieh DC, Sung FC, Kao CH. Advanced complicated diabetes mellitus is associated with a reduced risk of thoracic and abdominal aortic aneurysm rupture: a population-based cohort study. Diabetes Metab Res Rev. 2015 Feb;31(2):190-7.

37 Ailawadi G, Eliason JL, Roelofs KJ, Sinha I, Hannawa KK, Kaldjian EP, et al. Gender differences in experimental aortic aneurysm formation. Arterioscler Thromb Vasc Biol. 2004 Nov;24(11):2116-22.

38 Norman PE, Powell JT. Abdominal aortic aneurysm: the prognosis in women is worse than in men. Circulation. 2007 Jun;115(22): 2865-9.

39 Chau KH, Elefteriades JA. Natural history of thoracic aortic aneurysms: size matters, plus moving beyond size. Prog Cardiovasc Dis. 2013 Jul-Aug;56(1):74-80.

40 Jiménez-Trujillo I, González-Pascual M, Jiménez-García R, Hernández-Barrera V, de Miguel-Yanes JM, Méndez-Bailón M, et al. Type 2 Diabetes Mellitus and Thoracic Aortic Aneurysm and Dissection: An Observational Population-Based Study in Spain From 2001 to 2012. Medicine (Baltimore). 2016 May; 95(18):e3618.

41 Prakash SK, Pedroza C, Khalil YA, Milewicz DM. Diabetes and reduced risk for thoracic aortic aneurysms and dissections: a nationwide case-control study. J Am Heart Assoc. 2012 Apr;1(2):jah3-e000323.

42 Takagi H, Umemoto T; ALICE (All-Literature Investigation of Cardiovascular Evidence) Group. Negative Association of Diabetes With Thoracic Aortic Dissection and Aneurysm. Angiology. 2017 Mar;68(3):21624.
43 Pafili K, Gouni-Berthold I, Papanas N, Mikhailidis DP. Abdominal aortic aneurysms and diabetes mellitus. J Diabetes Complications. 2015 Nov-Dec;29(8):1330-6.

44 Kent KC. Clinical practice. Abdominal aortic aneurysms. N Engl J Med. 2014 Nov;371(22): 2101-8.

45 Singh K, Bønaa KH, Jacobsen BK, Bjørk L, Solberg S. Prevalence of and risk factors for abdominal aortic aneurysms in a populationbased study : the Tromsø Study. Am J Epidemiol. 2001 Aug;154(3):236-44.

46 De Rango P, Farchioni L, Fiorucci B, Lenti M. Diabetes and abdominal aortic aneurysms. Eur J Vasc Endovasc Surg. 2014 Mar;47(3): 243-61.

47 Golledge J, Cooper ME, Chai Z. Diabetes and Aortic Aneurysm. Angiology. 2016 Jul;67(6): 510-2.

48 Le MT, Jamrozik K, Davis TM, Norman PE. Negative association between infra-renal aortic diameter and glycaemia: the Health in Men Study. Eur J Vasc Endovasc Surg. 2007 May; 33(5):599-604.

49 De Rango P, Cao P, Cieri E, Parlani G, Lenti M, Simonte G, et al.; Comparison of surveillance vs. Aortic Endografting for Small Aneurysm Repair (CAESAR) investigators group. Effects of diabetes on small aortic aneurysms under surveillance according to a subgroup analysis from a randomized trial. J Vasc Surg. 2012 Dec;56(6):1555-63.

50 Miyama N, Dua MM, Yeung JJ, Schultz GM, Asagami T, Sho E, et al. Hyperglycemia limits experimental aortic aneurysm progression. J Vasc Surg. 2010 Oct;52(4):975-83.

51 Choke E, Thompson MM, Dawson J, Wilson WR, Sayed S, Loftus IM, et al. Abdominal aortic aneurysm rupture is associated with increased medial neovascularization and overexpression of proangiogenic cytokines. Arterioscler Thromb Vasc Biol. 2006 Sep;26(9): 2077-82.

52 Motoki T, Kurobe H, Hirata Y, Nakayama T, Kinoshita H, Rocco KA, et al. PPAR- $\gamma$ agonist attenuates inflammation in aortic aneurysm patients. Gen Thorac Cardiovasc Surg. 2015 Oct; $63(10): 565-71$.

53 Quinn CE, Hamilton PK, Lockhart CJ, McVeigh GE. Thiazolidinediones: effects on insulin resistance and the cardiovascular system. Br J Pharmacol. 2008 Feb;153(4):636-45.

54 Tenenbaum A, Fisman EZ. Balanced panPPAR activator bezafibrate in combination with statin: comprehensive lipids control and diabetes prevention? Cardiovasc Diabetol. 2012 Nov;11(1): 140.

55 Duval C, Chinetti G, Trottein F, Fruchart JC, Staels B. The role of PPARs in atherosclerosis. Trends Mol Med. 2002 Sep;8(9):422-30.

56 Charo IF. Macrophage polarization and insulin resistance: PPARgamma in control. Cell Metab. 2007 Aug;6(2):96-8. 
57 Jones A, Deb R, Torsney E, Howe F, Dunkley $\mathrm{M}$, Gnaneswaran Y, et al. Rosiglitazone reduces the development and rupture of experimental aortic aneurysms. Circulation. 2009 Jun;119(24):3125-32.

58 Pirianov G, Torsney E, Howe F, Cockerill GW. Rosiglitazone negatively regulates c-Jun $\mathrm{N}$-terminal kinase and toll-like receptor 4 proinflammatory signalling during initiation of experimental aortic aneurysms. Atherosclerosis. 2012 Nov;225(1):69-75.

59 Dhanasekaran DN, Reddy EP. JNK signaling in apoptosis. Oncogene. 2008 Oct;27(48): 6245-51.

60 Zhou G, Myers R, Li Y, Chen Y, Shen X, Fenyk-Melody J, et al. Role of AMP-activated protein kinase in mechanism of metformin action. J Clin Invest. 2001 Oct;108(8):116774.

61 Vasamsetti SB, Karnewar S, Kanugula AK, Thatipalli AR, Kumar JM, Kotamraju S. Metformin inhibits monocyte-to-macrophage differentiation via AMPK-mediated inhibition of STAT3 activation: potential role in atherosclerosis. Diabetes. 2015 Jun;64(6): 2028-41.
62 Li L, Mamputu JC, Wiernsperger N, Renier G. Signaling pathways involved in human vascular smooth muscle cell proliferation and matrix metalloproteinase-2 expression induced by leptin: inhibitory effect of metformin. Diabetes. 2005 Jul;54(7):2227-34.

63 Fujimura N, Xiong J, Kettler EB, et al. Metformin treatment status and abdominal aortic aneurysm disease progression. J Vasc Surg. 2016;64(1):46-54. e48.

64 Golledge J, Moxon J, Pinchbeck J, Anderson G, Rowbotham S, Jenkins J, et al. Association between metformin prescription and growth rates of abdominal aortic aneurysms. $\mathrm{Br} \mathrm{J}$ Surg. 2017 Oct;104(11):1486-93.

65 Chinda K, Palee S, Surinkaew S, Phornphutkul M, Chattipakorn S, Chattipakorn N. Cardioprotective effect of dipeptidyl peptidase-4 inhibitor during ischemia-reperfusion injury. Int J Cardiol. 2013 Jul;167(2):451-7.

66 Bao W, Morimoto K, Hasegawa T, Sasaki N, Yamashita T, Hirata K, et al. Orally administered dipeptidyl peptidase-4 inhibitor (alogliptin) prevents abdominal aortic aneurysm formation through an antioxidant effect in rats. J Vasc Surg. 2014 Apr;59(4):1098-108.
67 McCormick ML, Gavrila D, Weintraub NL. Role of oxidative stress in the pathogenesis of abdominal aortic aneurysms. Arterioscler Thromb Vasc Biol. 2007 Mar;27(3): 461-9.

68 Lu HY, Huang CY, Shih CM, Chang WH, Tsai CS, Lin FY, et al. Dipeptidyl peptidase-4 inhibitor decreases abdominal aortic aneurysm formation through GLP-1-dependent monocytic activity in mice. PLoS One. 2015 Apr;10(4):e0121077.

69 Hsu CY, Su YW, Chen YT, Tsai SH, Chang CC, Li SY, et al. Association between use of oral-antidiabetic drugs and the risk of aortic aneurysm: a nested case-control analysis. Cardiovasc Diabetol. 2016 Sep;15(1): 125.

70 Xiong J, Wu Z, Chen C, Wei Y, Guo W. Association between diabetes and prevalence and growth rate of abdominal aortic aneurysms: A meta-analysis. Int J Cardiol. 2016 Oct:221:484-95.

71 Takagi H, Umemoto T. A contemporary meta-analysis of the association of diabetes with abdominal aortic aneurysm. Int Angiol. 2015 Aug;34(4):375-82. 